\title{
A Narrative Summary of High Flow Nasal Cannula Therapy in the Adult Population
}

Joshua Gonzales

Texas State University, jg61@txstate.edu

Kevin Collins

Texas State University, kc35@txstate.edu

Christopher Russian

Texas State University, cr23@txstate.edu

Follow this and additional works at: https://nsuworks.nova.edu/ijahsp

Part of the Medicine and Health Sciences Commons

\section{Recommended Citation}

Gonzales J, Collins K, Russian C. A Narrative Summary of High Flow Nasal Cannula Therapy in the Adult Population. The Internet Journal of Allied Health Sciences and Practice. 2017 Jan 01;15(1), Article 8.

This Review Article is brought to you for free and open access by the College of Health Care Sciences at NSUWorks. It has been accepted for inclusion in Internet Journal of Allied Health Sciences and Practice by an authorized editor of NSUWorks. For more information, please contact nsuworks@nova.edu. 


\title{
A Narrative Summary of High Flow Nasal Cannula Therapy in the Adult Population
}

\begin{abstract}
Purpose: The aim of this narrative review is to outline the mechanism of action of HFNC therapy, the clinical benefits of its use, cautions of its clinical application and limitations of previous research. Methods: A literature review was conducted using the following databases as sources: Medline, PubMed, and Google Scholar. Only publications written in English were used in this clinical review. Keywords used in the search included the following: high-flow nasal cannula, heated humidified oxygen, oxygen therapy, non-invasive ventilation, and respiratory failure. Results: The literature reveals HFNC therapy significantly decreased the use of mechanical ventilation (invasive or non-invasive) in patients experiencing respiratory failure. HFNC therapy was better tolerated by patients and decreased the patient's work of breathing when compared to a conventional oxygen therapy (i.e., non-rebreather oxygen mask). Other clinical benefits of using HFNC when changing a patient from conventional facemask oxygen therapy to a HFNC device are significant improvements in $\mathrm{PaO} 2$, respiratory rate and overall comfort. Conclusions: High flow nasal cannula (HFNC) therapy serves as an alternative to conventional oxygen therapy to deliver elevated concentrations of oxygen to patients experiencing acute respiratory failure. Information detailed in this article suggests HFNC therapy is an effective therapy for improving a patient's oxygenation status when experiencing acute respiratory failure in adults. The literature reveals, it is reasonable to initiate HFNC in adults with acute hypoxemic respiratory failure without hypercapnia, as an alternative to standard oxygen therapy or noninvasive positive pressure ventilation.
\end{abstract}

\section{Author Bio(s)}

Joshua F. Gonzales, MHA, RRT-NPS, RRT-SDS, is an Associate Professor of Respiratory Care in the College of Health Professions at Texas State University in San Marcos, TX. He is a licensed respiratory care practitioner in the state of Texas.

Kevin P. Collins, MSc, RRT-RPFT, AE-C, is an Associate Professor of Respiratory Care in the College of Health Professions at Texas State University in San Marcos, TX. He is a licensed respiratory care practitioner in the state of Texas.

Christopher J. Russian, Ph.D., RRT-NPS, RPSGT, RST, is a Professor of Respiratory Care in the College of Health Professions at Texas State University in San Marcos, TX. He is a licensed respiratory care practitioner in the state of Texas. 


\title{
IJAHSP \\ The Internet Joưnal of Allied Health Sciences and Practice
}

Dedicated to allied health professional practice and education

Vol. 15 No. 1 ISSN 1540-580X

\section{A Narrative Summary of High Flow Nasal Cannula Therapy in the Adult Population}

\author{
Joshua Gonzales, MHA, RRT-NPS, RRT-SDS \\ Kevin Collins, MSc, RRT-RPFT, AE-C \\ Christopher Russian, Ph.D., RRT-NPS, RPSGT, RST \\ Texas State University \\ United States
}

\begin{abstract}
Purpose: The aim of this narrative review is to outline the mechanism of action of HFNC therapy, the clinical benefits of its use, cautions of its clinical application and limitations of previous research. Methods: A literature review was conducted using the following databases as sources: Medline, PubMed, and Google Scholar. Only publications written in English were used in this clinical review. Keywords used in the search included the following: high-flow nasal cannula, heated humidified oxygen, oxygen therapy, non-invasive ventilation, and respiratory failure. Results: The literature reveals HFNC therapy significantly decreased the use of mechanical ventilation (invasive or non-invasive) in patients experiencing respiratory failure. HFNC therapy was better tolerated by patients and decreased the patient's work of breathing when compared to a conventional oxygen therapy (i.e., nonrebreather oxygen mask). Other clinical benefits of using HFNC when changing a patient from conventional facemask oxygen therapy to a HFNC device are significant improvements in $\mathrm{PaO} 2$, respiratory rate, and overall comfort. Conclusions: High flow nasal cannula (HFNC) therapy serves as an alternative to conventional oxygen therapy to deliver elevated concentrations of oxygen to patients experiencing acute respiratory failure. Information detailed in this article suggests HFNC therapy is an effective therapy for improving a patient's oxygenation status when experiencing acute respiratory failure in adults. The literature reveals that it is reasonable to initiate HFNC in adults with acute hypoxemic respiratory failure without hypercapnia as an alternative to standard oxygen therapy or noninvasive positive pressure ventilation.
\end{abstract}

\section{INTRODUCTION}

Oxygen therapy is the primary treatment for patients suffering from hypoxemia. ${ }^{1,2}$ Conventional forms of oxygen therapy utilize various delivery interfaces while supplying increased concentrations of oxygen above ambient levels. Considered an alternative to these oxygenation modalities, high-flow nasal cannula (HFNC) devices were developed to supply the patient with above ambient levels of oxygen concentrations while delivering heated humidified gas at inspiratory flow rates of up to $60 \mathrm{lpm}$. Numerous clinic trials have reported increased patient comfort and therapeutic benefits of HFNC therapy, particularly in patients suffering from respiratory failure secondary to hypoxemia. ${ }^{3-5}$ In contrast to the published research outlining the therapeutic benefits of HFNC therapy, other researchers argue the delay of invasive and non-invasive ventilation strategies is linked to HFNC therapy. ${ }^{6}$ Similarly, limitations to previous HFNC research also create room for caution. ${ }^{7}$

It is well established in medicine that oxygen therapy is the drug of choice for patients with low oxygen saturation. The gap that exists, in our opinion, is on the specific role of HFNC therapy as an adjunct for oxygen delivery. The theoretical framework for this narrative review is built upon systems therapy and the relationship between HFNC therapy and clinical outcomes (e.g. $\mathrm{PaO} 2, \mathrm{FiO}$, vital signs, $\mathrm{SpO}$, etc.). The objective of this narrative review is to summarize research related to HFNC therapy. The research question to be considered is, "What clinical indices are positively impacted when using HFNC therapy for adult patients experiencing acute hypoxemic respiratory failure?" The aim of this narrative summary will extend beyond the clinical benefits of HFNC therapy and review the mechanism of action of HFNC therapy and the cautions during clinical application. Where appropriate, the article will compare HFNC therapy to conventional oxygen therapy and non-invasive ventilation strategies. For the purposes of this review, conventional oxygen therapy is referring to traditional low-flow (nasal cannula, non-

(C) The Internet Journal of Allied Health Sciences and Practice, 2017 
rebreather mask, and simple $\mathrm{O} 2$ mask) and high-flow (venturi-mask) oxygen modalities. These devices provide supplemental oxygen therapy to patients requiring above ambient oxygen levels.

\section{METHODS}

A literature review was conducted in March of 2016 using a variety of databases (Medline $₫$, PubMed $₫$, and Google Scholar) with no limitation to publication year set. The open publication year was done primarily to include previous research that describes the basic principles of humidification and oxygen therapy. The study design of the literature search included clinical trials, bench-top research trials, clinical practice guidelines, and previously performed literature reviews. Only research publications written in English were included in this literature review. Keywords used in the search included high-flow nasal cannula, high-flow nasal cannula therapy, and humidified oxygen. Table 1 outlines the PICO (Patient, Intervention, Comparison, and Outcome) search criteria used for the literature review.

\begin{tabular}{|l|l|}
\hline \multicolumn{2}{|c|}{ PICO Criteria } \\
\hline Patient & $\begin{array}{l}\text { All age group populations were considered for review in patients utilizing HFNC therapy who were } \\
\text { experiencing acute respiratory failure. }\end{array}$ \\
\hline Intervention & $\begin{array}{l}\text { Previously published research was included if HFNC therapy was used to provide supplemental oxygen } \\
\text { therapy for patients experiencing acute respiratory failure. }\end{array}$ \\
\hline Comparison & $\begin{array}{l}\text { Additional research was included in clinical situations where HFNC therapy was compared to non-invasive } \\
\text { ventilation and traditional oxygen therapy. }\end{array}$ \\
\hline Outcome & $\begin{array}{l}\text { All patient-relevant outcomes of described interventions and comparisons where reviewed as part of this } \\
\text { literature search. }\end{array}$ \\
\hline
\end{tabular}

Literature search results were combined following completion of database searches. All duplicate articles were removed from the combined pool of gathered articles prior to review. Articles were initially considered for use based on a review of the title, abstract, and criteria outlined in the PICO search criteria. All remaining articles were reviewed by the authors for consideration for inclusion in this literature search.

\section{Quality Assessment}

Each article considered for use in the literature review was assessed for quality assurance. Impact factors (IF), Article Influence Scores (AIS), and Eigenfactor Scores (ES) were reviewed for each (Table 2). ${ }^{8}$ Only previously published peer-reviewed articles were used in this literature review.

\begin{tabular}{|l|c|c|c|}
\hline \multicolumn{1}{|c|}{ Journal Name } & Impact Factor & $\begin{array}{c}\text { Article Influence } \\
\text { Score }\end{array}$ & $\begin{array}{c}\text { Eigenfactor } \\
\text { Score }\end{array}$ \\
\hline Respiratory Care & 1.92 & 55 & 77 \\
\hline Clinical Medicine & 1.65 & 43 & 54 \\
\hline Minerva Anestesiologica & 2.134 & 50 & 70 \\
\hline Respiratory Medicine & 3.036 & 76 & 91 \\
\hline Intensive Care Medicine & 10.125 & 93 & 95 \\
\hline American Journal of Respiratory and Critical Care Medicinea & 13.118 & 98 & 99 \\
\hline Journal of Critical Care & 2.445 & 68 & 82 \\
\hline European Respiratory Journal & 8.332 & 95 & 97 \\
\hline Journal of Perinatology & 2.087 & 68 & 82 \\
\hline British Journal of Anesthesia & 5.616 & 88 & 93 \\
\hline Critical Care & 4.95 & 92 & 97 \\
\hline Journal of Intensive Care Medicine & 3.262 & $\mathrm{~N} / \mathrm{A}$ & $\mathrm{N} / \mathrm{A}$ \\
\hline Archives of Disease in Childhood & 3.321 & $\mathrm{~N} / \mathrm{A}$ & $\mathrm{N} / \mathrm{A}$ \\
\hline Surgery, Gynecology, and Obstetricsb & 4.257 & 94 & 96 \\
\hline a. Previously known as the American Review of Respiratory Disease Journal & \\
b. The journal has now changed its name to the Journal of the American College of Surgeons & \\
\hline
\end{tabular}




\section{RESULTS}

Results of the literature review revealed 520 combined "hits." Duplicates and abstract only "hits" were removed from consideration. Remaining articles were assessed by the authors using the outlined PICO search criteria to fit the target goal of the literature review. All remaining articles post PICO search criteria were reviewed by the authors to assess the IF, AIS, and ES. All remaining articles post review were included in this literature review. Information from these articles includes details outlining study methodology and significance of research findings. Objective outcomes reported in this clinical review include changes in partial pressure of arterial oxygen ( $\mathrm{PaO} 2)$, pulse oximetry analysis, improvements in work of breathing, oxygenation index, and patient tolerance to HFNC therapy. The articles included in this publication add to the focus of this manuscript.

\section{HFNC Mechanism of Action}

High flow nasal cannula therapy can be applied to different age groups, encompassing a variety of different disease processes. The benefits of HFNC therapy are better understood with a discussion of the mechanisms of action. Dysart et al outlined the mechanisms of action into five categories: 1) a reduction of deadspace, 2) a reduction of resistance, 3) improved pulmonary mechanics, 4) a reduction of metabolic cost, and 5) distending airway pressure. ${ }^{9}$ Each of these mechanisms will be discussed below.

High flow nasal cannula therapy systems are capable of providing oxygen flow rates that are significantly higher than traditional low flow nasal cannula devices. ${ }^{1}$ The delivery of high flow rates to the nasopharyngeal passages aids in the reduction in deadspace by creating tracheal gas insufflation (TGI). ${ }^{10}$ It has been reported that TGI further eliminates excess $\mathrm{CO}_{2}$ that remains in a patient's airway on exhalation. ${ }^{11}$ Because of this removal, less $\mathrm{CO}_{2}$ will be re-inhaled by the patient on subsequent breaths. ${ }^{12}$ Wettstein et al researched the effects of open mouth breathing versus closed mouth breathing in patients using HFNC therapy. ${ }^{13}$ Their research discovered an increase in $\mathrm{FiO}_{2}$ in open mouth breathing patients. As a result, it was hypothesized that this increase in $\mathrm{FiO}_{2}$ was due to the reservoir effect of the nasal pharynx and oral cavity. It is believed that open mouth breathing while wearing a HFNC system allows for a more efficient elimination of $\mathrm{CO} 2 .{ }^{13}$ Thus, HFNC therapy has the ability to washout $\mathrm{CO} 2$ and increase FiO2 within the anatomical deadspace.

Another mechanism of action of HFNC therapy includes a reduction of resistance in the patient's nasopharyngeal passages. Patients experiencing respiratory failure often have an increase in work of breathing, elevated inspiratory flow rates and an increase in oxygen demands. Previous findings have reported a decrease in patient inspiratory flow rates in instances when high-flow oxygen therapy was used. ${ }^{14}$ The high oxygen flow rates delivered with HFNC therapy likely reduces inspiratory airway resistance by providing nasopharyngeal flow rates that exceed patient inspiratory demands. ${ }^{9}$ Vargas et al reported a reduction in inspiratory muscle effort and work of breathing in patients using HFNC therapy. ${ }^{15}$ Similarly, Sztrymf et al reported a significant reduction in work of breathing in patients experiencing respiratory failure when placed on heated HFNC therapy systems. ${ }^{16}$

Previous research indicates that a lack of heated humidity to the nasopharyngeal passages can cause bronchoconstriction and a decrease in lung compliance. ${ }^{17}$ It has been reported that cold air delivered to the nasal cavity induced a vagally mediated bronchoconstriction in smoking, non-smoking, and patients diagnosed with COPD. ${ }^{18}$ The heated humidity provided in HFNC systems has been shown to improve pulmonary mechanics by effectively providing the patient with heated humidity at very high inspiratory flow rates. Ricard \& Boyer reported better patient tolerance with oxygen flow rates of up to 60 Ipm when the dry gas was heated and humidified..$^{19}$

Additional research reported an increased pulmonary compliance level in patients receiving HFNC therapy compared to patients using $6 \mathrm{cmH}_{2} \mathrm{O}$ via continuous positive airway pressure. ${ }^{20}$ Chikata et al researched two HFNC therapy devices, the Airvo 2 and Optiflow system (Fisher \& Paykel Healthcare, Auckland, New Zealand). ${ }^{21}$ The researchers tested humidity level at flow rates of 20 , 40 and $50 \mathrm{lpm}$. The absolute humidity levels for the Airvo 2 at 20,40 and $50 \mathrm{lpm}$ were $35.3 \pm 2.0 \mathrm{mg} / \mathrm{L}, 37.1 \pm 2.1 \mathrm{mg} / \mathrm{L}$, and 37.6 $\pm 2.1 \mathrm{mg} / \mathrm{L}$, respectively. Results of the Optiflow indicated an absolute humidity level of $33.1 \pm 1.5 \mathrm{mg} / \mathrm{L}, 35.9 \pm 1.7 \mathrm{mg} / \mathrm{L}$, and 36.2 $\pm 1.8 \mathrm{mg} / \mathrm{L}$ at flow rates of 20,40 and $50 \mathrm{lpm}$, respectively. The results of their research indicated that sufficient heated humidity was supplied at flow rates of up to $50 \mathrm{lpm}$ in the two HFNC systems.

Dysart et al reported a reduction in metabolic cost of gas conditioning in patients using HFNC therapy. ${ }^{9}$ Under normal respiratory conditions, inspired gases are heated and humidified by the nasopharyngeal passages until $100 \%$ relative humidity is obtained. ${ }^{22}$ HFNC therapy provides heated humidified gases to the nasopharyngeal passages that would minimize the amount of energy exerted by the body to heat the delivered gas. It is estimated that an adult patient breathing 500 mls of gas at 12 breaths per minute burns 156 calories per minute warming and humidifying delivered dry gases. ${ }^{9}$ Previous research has indicated improved patient weight gain when placed on HFNC therapy. ${ }^{23}$ Furthermore, there is a reduced oxygen requirement associated with the delivery of heated humidified oxygen because of a reduced energy requirement by the patient's body to warm and humidify the gas. ${ }^{9}$

(C) The Internet Journal of Allied Health Sciences and Practice, 2017 
Lastly, distal airway pressures are generated in patients using HFNC therapy that may contribute to a reduction in oxygen concentration requirements. Positive end-expiratory pressure generated in a patient's airways will increase alveolar recruitment and increase a patient's oxygenation status. ${ }^{24}$ In a comparison study, Corley et al researched the differences in end-expiratory lung volume and airway pressures when using low-flow and HFNC systems. ${ }^{25}$ Their findings indicated an increase of $25.6 \%$ in end-expiratory lung volume and pressure measurements of $3.0 \mathrm{cmH}_{2} \mathrm{O}$ when switching from low-flow oxygen to HFNC therapy. 25 In a bench-top trial of HFNC therapy, Parke and McGuinness reported an elevation in expiratory pressure when using flow rates of 30,40 , and $50 \mathrm{lpm} .{ }^{26}$ Results of their research indicated flowrates of 30,40 , and $50 \mathrm{lpm}$ produced airway pressures with a mean $\pm \mathrm{SD}$ of $1.93 \pm 1.25 \mathrm{cmH}_{2} \mathrm{O}, 2.58 \pm 1.54 \mathrm{cmH}_{2} \mathrm{O}$, and $3.31 \pm 1.05 \mathrm{cmH}_{2} \mathrm{O}$, respectively. Further research by Parke et al reported pressure measurements when using flow rates up to $100 \mathrm{lpm}$. ${ }^{27}$ Their findings report a mean \pm SD airway pressures of $2.7 \pm 0.7$ to $11.9 \pm 2.7 \mathrm{cmH} 2 \mathrm{O}$ when using flow rate ranges of 30 to $100 \mathrm{lpm} .{ }^{27}$

\section{Clinical Benefits of HFNC Therapy}

The available literature describes the therapeutic benefits of HFNC therapy. In a retrospective analysis, Nagata et al reviewed data from respiratory failure patients before and after the introduction of HFNC therapy. ${ }^{28}$ The study results demonstrated HFNC therapy significantly decreased the use of mechanical ventilation (invasive or non-invasive) in patients experiencing respiratory failure $(p<$ .01). Also, a significant reduction in ventilator free days $(p<.01)$ and ventilator required days $(p<.05)$ was reported once HFNC therapy was introduced to the hospital. HFNC therapy did not reduce length of ICU/intermediate care unit days $(p=.80)$, did not reduce hospital length of stay $(p=.33)$, and did not increase hospital mortality rate $(p=.26) .{ }^{28}$

Roca et al revealed a clinical benefit when changing a patient from conventional facemask oxygen therapy to a HFNC device. ${ }^{5}$ The research results revealed significant improvements in $\mathrm{PaO} 2(p=.002)$, respiratory rate $(p<.001)$ and overall comfort $(p<.001)$ when switched from oxygen therapy via facemask to HFNC. Additionally, patients given HFNC therapy demonstrated a significant decrease in dyspnea $(p=.001)$ and dry mouth $(p<.001)$. There were no significant changes in heart rate $(p>.99)$ or mean arterial pressure $(p>.36) . .^{5}$

Parke et al also compared HFNC therapy to conventional facemask therapy. ${ }^{3}$ They reported HFNC therapy to be a more effective treatment for mild to moderate hypoxemic respiratory failure when compared to oxygen therapy via facemask. ${ }^{3}$ It was reported that patients using HFNC therapy had a reduction in need for non-invasive ventilation when compared to facemask therapy (HFNC $=10 \%$, Facemask $=3 \%, p=.10)$. Also, patients experienced significantly fewer $(p=0.009)$ oxygen desaturation episodes when using HFNC therapy. ${ }^{3}$

Rittayamai et al compared $6 \mathrm{lpm}$ of oxygen via nasal cannula to $35 \mathrm{lpm}$ of HFNC therapy. ${ }^{29}$ Results indicated levels of dyspnea significantly improved with HFNC therapy $(p=.01)$. Patients using HFNC therapy reported reductions in breathing frequency $(p=.82)$ and heart rate $(p=0.04)$. Significant improvements $(p=0.01)$ were reported in patient comfort levels when HFNC was compared to standard nasal cannula therapy. ${ }^{29}$

Sztrymf et al compared HFNC therapy to a non-rebreather oxygen mask in patients experiencing acute respiratory failure. ${ }^{16}$ Outcomes were assessed by monitoring patient heart rate, work of breathing, intercostal retractions, and oxygen parameters. Results indicated positive patient outcomes, in some instances as early as 15 minutes, after initiation of HFNC therapy. The authors reported HFNC significantly increased $\mathrm{PaO} 2(p=0.009)$ and $\mathrm{PaO} / \mathrm{FiO} 2(p=0.036)$ in comparison to the patient's baseline oxygenation status. Results also indicated HFNC therapy was better tolerated by patients and decreased the patient's work of breathing when compared to a conventional non-rebreather oxygen mask. ${ }^{16}$

Vargas et al researched clinical outcomes in patients using a conventional non-rebreather mask, a continuous positive airway pressure (CPAP) level of $5 \mathrm{cmH}_{2} \mathrm{O}$ and $\mathrm{HFNC}$ systems. ${ }^{15}$ The authors reported a significant reduction in inspiratory effort $(p<.01)$ when patients were moved from a non-rebreather mask to either HFNC therapy or a CPAP level of $5 \mathrm{cmH}_{2} \mathrm{O}$. Also, patients showed a significant increase in $\mathrm{PaO} 2 / \mathrm{FiO} 2$ ratio $(p<.01)$ when switched from a non-rebreather to HFNC therapy. CPAP therapy revealed a significantly higher improvement in $\mathrm{PaO} 2 / \mathrm{FiO} 2$ than HFNC therapy. It was also reported that patient's respiratory rates significantly $(p<.01)$ reduced when switched to HFNC. The reduction in respiratory rate from CPAP therapy to HFNC therapy was not significant. ${ }^{15}$

Additional research compared HFNC therapy, non-invasive ventilation, and conventional non-rebreathing face mask. Results indicated a significant increase in $\mathrm{PaO} 2(\mathrm{p}<.01)$ in patients moving from a conventional non-rebreathing face mask to HFNC therapy or to non-invasive ventilation. The PaO2/FiO2 ratio did not increase with HFNC therapy. It did, however, improve with noninvasive ventilation $(p<.01)$ when compared to HFNC therapy values. It was also reported that HFNC therapy was tolerated significantly better when compared to non-invasive ventilation $(p=.004){ }^{6}$

(C) The Internet Journal of Allied Health Sciences and Practice, 2017 
Another area of study is the clinical benefit of HFNC therapy following extubation. Rittayamai et al compare short term benefits of HFNC and non-rebreather oxygen mask following the extubation of 17 patient volunteers..$^{30} \mathrm{At}$ the conclusion of the research, it was reported that patients using HFNC after extubation had a significant decrease in respiratory rate $(p=.009)$, heart rate $(p=$ $.006)$, and shortness of breath $(p=.04$ ) when compared to a non-rebreather mask. Of the 17 patient participants, $88.2 \%$ preferred HFNC therapy over a non-rebreather mask following extubation. The research also reported no significant differences in oxygen saturation and mean arterial blood pressure between the participants using the two devices. ${ }^{21}$ In a similar study, Maggiore et al compared the benefits of HFNC versus an oxygen venturi-mask post-extubation. ${ }^{31}$ Their results demonstrated that patients using HFNC following extubation had a significant increase in PaO2/FiO2 ratio at the $24(p=.03), 36(p=.0003)$, and $48(p=.01)$ hour marks. Also, significantly fewer patients required reintubation $(p<.01)$ or non-invasive ventilation $(p=.04)$ when using HFNC versus venture-mask. ${ }^{31}$

\section{Cautions of HFNC Therapy}

Despite the listed clinical benefits of HFNC therapy, clinical implementation of HFNC therapy needs to be carefully considered. One concern associated with HFNC therapy is delaying invasive and non-invasive ventilation after the initiation of HFNC therapy. Previous HFNC therapy research has failed to show a reduction in intubation rates in acute respiratory failure patients when compared to non-invasive ventilation. Kang et al enrolled 175 patients in a clinical trial investigating extubation rates and ICU mortality in patients using HFNC therapy. ${ }^{32}$ Research participants were classified into two groups based on intubation times after initiation of HFNC therapy (less than 48 hours or greater than 48 hours). Results indicated that patients intubated prior to 48 hours of initiation of HFNC therapy had better weaning outcomes $(p=.002)$, better extubation success $(p=.006)$, and better ICU mortality rates $(p=.001)$. This research suggests that HFNC therapy may bring risk to the patient if more aggressive treatment options are delayed. ${ }^{32} \mathrm{~A}$ similar study by Frat et al investigated HFNC therapy as the initial therapy for non-hypercapnic hypoxemia. ${ }^{6}$ Results indicated $36 \%$ of patients experiencing acute respiratory failure required intubation after the use HFNC therapy. The authors reported a median intubation time of 30 hours after initiation of HFNC therapy. Symptoms of patients intubated in the study included worsening respiratory distress, respiratory arrest, and shock. ${ }^{6}$

Research by Lemaile et al compared HFNC to high-flow facemask therapy via a venturi-mask. ${ }^{33}$ Their finding reported no significant difference in the need for invasive ventilation and non-invasive ventilation when comparing HFNC therapy to the use of a high-flow venturi-mask $(p=.36) .^{33}$ Of the 84 patients investigated, 52 received HFNC therapy, whereas 48 received oxygen therapy via venturi-mask. At the completion of a two-hour study period, $15 \%$ of HFNC therapy patients and $8 \%$ of venturi-mask patients required invasive or non-invasive ventilation. Moreover, there was no difference in heart rate (HFNC = 98 bpm, venturi - 99 bpm), respiratory rate (25 bpm), and dyspnea score (3) when comparing HFNC therapy to oxygen venturi-mask. ${ }^{33}$

Research by Jones et al compared HFNC therapy to standard oxygen therapy. ${ }^{34}$ Standard oxygen devices included venturi-mask, Hudson aerosol mask, or nasal cannula. ${ }^{34}$ Starting flow rate for HFNC therapy was $40 \mathrm{lpm}$ with an oxygen concentration of $28 \%$ at $37 \mathrm{C}$. Of the patients included in the research, $3.6 \%$ of HFNC therapy patients and $7.8 \%$ standard oxygen patients required the use of non-invasive or invasive ventilation $(p=.16)$. There was also no difference in emergency department length of stay (4.5 hours HFNC therapy, 4.9 hours in standard oxygen). Their research failed to show a reduction in non-invasive and invasive mechanical ventilation in patients experiencing acute respiratory failure in an emergency department when comparing HFNC therapy to standard oxygen. ${ }^{34}$

\section{IMPLICATIONS FOR FUTURE RESEARCH}

Further research is warranted to better understand the efficacy of HFNC therapy on a wide variety of pulmonary complications. Although promising research has been performed, clinical guidelines for HFNC therapy for specific patient disease processes has yet to be defined. Publications reviewed in this article focus primarily on acute respiratory failure patients. Further research is recommended to establish the efficacy of HFNC with a variety of different breathing patterns, heart rates, work of breathing, etc.

In addition, further research is warranted to determine pressures and flowrates created at the alveolar level with HFNC therapy. Parke et al determined pressures generated by HFNC therapy by placing a catheter behind a patient's uvula. ${ }^{35}$ Bench-top research is needed to determine positive end-expiratory pressure and inspiratory flowrates delivered to a patient's distal airways.

\section{LIMITATIONS}

This paper provided a narrative review of the available research based on our search criteria. It provides an in-depth summary of the clinical outcomes associated with HFNC therapy and other oxygen delivery systems. Meta-analysis of data from the included studies was not the intention of this project.

(C) The Internet Journal of Allied Health Sciences and Practice, 2017 


\section{CONCLUSION}

Information detailed in this article suggests HFNC therapy is an effective therapy for improving a patient's oxygenation status when experiencing acute respiratory failure in adults. The literature reveals that it is reasonable to initiate HFNC in adults with acute hypoxemic respiratory failure without hypercapnia as an alternative to standard oxygen therapy or noninvasive positive pressure ventilation. $36-38$ The mechanism of action of HFNC therapy encompasses many therapeutic benefits for patients experiencing respiratory distress. Benefits include a reduction in work of breathing, increased patient tolerance of therapy, and an increase patient oxygenation. Additional research is warranted to understand the full scope of HFNC therapy..

\section{References}

1. Kallstrom TJ. AARC clinical practice guidelines: oxygen therapy for adults in the acute care facility. Respir Care. 2002;47(6):717-20.

2. O'Driscoll BR, Howard LS, Davidson AG. Emergency oxygen use in adult patients: concise guidelines. Clin Med. 2011;11(4):372-5. [PMID: 21853838]

3. Parke RL, McGuinness SP, Eccleston ML. A preliminary randomized controlled trial to assess effectiveness of nasal highflow oxygen in intensive care patients. Respir Care. 2011;56(3):265-70. [PMID: 21255498]

4. Ricard JD. High flow nasal oxygen in acute respiratory failure. Minerva Anestesiol. 2012;78(7):836-41. doi 10.1007/s00134009-1457-9. [PMID: 22531566]

5. Roca O, Riera J, Torres F, Masclans JR. High-flow oxygen therapy in acute respiratory failure. Respir Care. 2010;55(4):40813. [PMID: 20406507]

6. Frat JP, Brugiere B, Ragot S, et al. Sequential application of oxygen therapy via high-flow nasal cannula and noninvasive ventilation in acute respiratory failure: an observational pilot study. Respir Care. 2015;60(2):170-8. [PMID: 25294935]

7. Roberts $\mathrm{CD}$, Oeckler RA. A skeptical perspective on high-flow nasal cannula in the treatment of acute hypoxemic respiratory failure. Respir Care. 2015;60(10):1522-5. doi: 10.4187/respcare.04473. [PMID: 26405189]

8. Kianifar H, Sadeghi R, Zarifmahmoudi L. Comparison between impact factor, eigenfactor metrics, and SCimago journal rank indicator of pediatric neurology journals. Acta Inform Med. 2014;22(2):103-6. [PMID: 24825934]

9. Dysart K, Miller TL, Wolfson MR, Shaffer TH. Research in high-flow therapy: mechanism of action. Respir Med. 2009;103(10):100-5. [PMID: 19467849]

10. Dassieu B, Brochard L, Agudze E, Patkai J, Janaud JC, Danan C. Continuous tracheal gas insufflation enables a volume reduction strategy in hyaline membrane disease: technical aspects and clinical results. Intensive Care Med. 1998;24(10):1076-82. [PMID: 9840243]

11. Hoffman LA, Miro AM, Tasota FJ, Delgado E, Zullo TG, Lutz J, Pinsky MR. (2000) Tracheal gas insufflation. Limits of efficacy in adults with acute respiratory distress syndrome. Am J Respir Crit Care Med. 2000;162(2):387-92. doi 10.1164/ajrccm.162.2.99010111. [PMID: 10934058]

12. Ravenscraft SA, Burke WC, Nahum A, Nakos G, Marcy TW, Marini JJ. Tracheal gas insufflation augments $\mathrm{CO} 2$ clearance during mechanical ventilation. Am Rev Respir Dis. 1993;148(2):345-51. doi 10.1164/ajrccm/148.2.345. [PMID: 8342897]

13. Wettstein RB, Shelledy DC, Peters JI. Delivered oxygen concentrations using low-flow and high-flow nasal cannulas. Respir Care. 2005;50(5):604-9. [PMID: 15871753]

14. Couser JI, Make BJ. Transtracheal oxygen decreases inspired minute ventilation. Am Rev Respir Dis. 1989;139(3):627-31. doi 10.1164/ajrccm/139.627. [PMID: 2923361]

15. Vargas F, Saint-Leger M, Boyer A, Bui NH, Hilbert G. Physiologic effects of high-flow nasal cannula oxygen in critical care subjects. Respir Care. 2015;60(10):1369-76. doi:10.4187/respcare.03814. [PMID: 25944940]

16. Sztrymf B, Messika J, Mayot T, Lenglet $H$, Dreyfess D, Ricard JD. Impact of high-flow nasal cannula oxygen therapy on intensive care unit patients with acute respiratory failure: a prospective observational study. J Crit Care. 2012;27(3):9-13. doi: 10.1016/j.jcrc.2011.07.075. [PMID: 21958974]

17. Fontanari $P$, Zattara-Hartmann $M C$, Burnet $H$, Jammes $Y$. Nasal eupnoeic inhalation of cold, dry air increases airway resistance in astmatic patients. European Respiratory Journal. 1997;10(10):2250-4. [PMID: 9387948]

18. On LS, Boonyongsunchai P, Webb S, Davies L, Claverely PM, Costello, RW. Function of pulmonary neuronal M2 muscarinic receptors in stable chronic obstructive pulmonary disease. Am J Respir Crit Care Med. 2011;162(6):1320-5.

19. Ricard JD, Boyer A. Humidification during oxygen therapy and non-invasive ventilation: do we need some and how much? Intensive Care Med. 2009;35(6):963-5. doi 10.1007/s00134-009-1457-9. [PMID: 19294364]

20. Saslow JG, Aghai ZH, Nakhla TA, et al. Work of breathing using high-flow nasal cannula in preterm infants. $J$ Perinatol. 2006;26(8):476-80. [PMID: 16688202]

21. Chikata Y, Izawa M, Okuda N, et al. Humidification performance of two high-flow nasal cannula devices: a bench study. Respir Care. 2015;59(8):1186-90. doi: 10.4187/respcare.02932. [PMID: 24368861]

22. Proctor DF. Handbook of Physiology-Respiration: Form and function of the upper airways.1986;1:63-73. Retrieved from http://www.comprehensivephysiology.com/WileyCDA/CompPhysArticle/refld-cp030306.html.

(C) The Internet Journal of Allied Health Sciences and Practice, 2017 
23. Holleman-Duray D, Kaupie D, Weiss MG. Heated humidified high-flow nasal cannula: use and a neonatal early extubation protocol. J Perinatol. 2007;27(12):776-81. [PMID: 17855805]

24. Toung TJ, Saharia P, Mitzner WA, Permutt S, Cameron JL. The beneficial and harmful effects of positive end expiratory pressure. Surg Gynecol Obstet. 1978;147(4):518-24. Retrieved from: http://www.ncbi.nlm.nih.gov/pubmed/3604477. [PMID: 360447]

25. Corley A, Caruana LR, Barnett AG, Tronstad O, Fraser JF. Oxygen delivery through high-flow nasal cannulae increase endexpiratory lung volume and reduce respiratory rate in post-cardiac surgical patients. Br J Anaesth. 2011;107(6):998-1004. doi: 10.1093/bja/aer265. [PMID: 21908497]

26. Parke RL, McGuiness SP. Pressures delivered by nasal high flow oxygen during all phases of the respiratory cycle. Respir Care. 2013;58(10):1621-4. doi: 10.4187/respcare.02358. [PMID: 23513246]

27. Parke R, Bloch A, McGuinness SP. Effect of very-high-flow nasal therapy on airway pressure and end-expiratory lung impedance in healthy volunteers. Respir Care. 2015;60 (10):1397-403. doi: 10.4187/respcare.04028. [PMID: 26329355]

28. Nagata $\mathrm{K}$, Morimoto $\mathrm{T}$, Fujimoto $\mathrm{D}$, et al. Efficacy of high-flow nasal cannula therapy in acute hypoxemic respiratory failure: decreased use of mechanical ventilation. Respir Care. 2015;60(10):1390-6. doi 10.4187/respcare.04026 [PMID: 26106206]

29. Rittayamai N, Tscheikuna J, Praphruetkit N, Kijpinyochai S. Use of high-flow nasal cannula for acute dyspnea and hypoxemia in the emergency department. Respir Care. 2015;60(10):1377-82. doi: 10.4187/respcare.03837. [PMID: 26060321]

30. Rittayamai N, Tscheikuna J, Rujiwit P. High-flow nasal cannula versus conventional oxygen therapy after endotracheal extubation: a randomized crossover physiologic study. Respir Care. 2014;59(4):485-90. doi: 10.4187/respcare.02397. [PMID: 24046462]

31. Maggiore SM, Idone FA, Vaschetto R, Festa R, et al. Nasal high-flow versus venture mask oxygen therapy after extubation: effects on oxygenation, comfort, and clinical outcome. Am J Respir Crit Care Med. 2014;190(3):282-8. doi: 10.1164/rccm.201402-0364OC. [PMID: 25003980]

32. Kang BJ, Koh Y, Lim CM, et al. Failure of high-flow nasal cannula therapy may delay intubation and increase mortality. Intensive Care Med. 2015;41(4):623-32. doi: 10.1007//s00134-015-3693-5. [PMID: 25691263]

33. Lemaile V, Mokart D, Mayaux J, et al. The effect of a 2-h trial of high-flow oxygen by nasal cannula versus venture mask in immunocompromised patients with hypoxemic acute respiratory failure: a multicenter randomized trial. Crit Care. 2015;19:380. doi: 10.1186/s13054-015-1097-0. [PMID: 26521922]

34. Jones PG, Kamona S, Doran O, Sawtell F, Wilsher M. Randomized controlled trial of humidified high-flow nasal oxygen for acute respiratory distress in the emergency department: the hot-er study. Respir Care. 2016;61(3):291-9. doi: 10.4187/respcare.04252. [PMID: 26577199]

35. Parke RL, Eccleston ML, McGuinness SP. The effects of flow on airway pressure during nasal high-flow oxygen therapy. Respir Care. 2011;56(8):1151-4. doi:10.4187/respcare.01106 [PMID: 21496369]

36. Lee JH, Rehder KJ, Williford L, Cheifetz IM, Turner DA. Use of high flow nasal cannula in critically ill infants, children, and adults: a critical review of the literature. Intensive Care Med. 2013;39(2):247-57. doi: 10.1007/s00134-012-2743-5. [PMID: 23143331]

37. Nishimura M. High-flow nasal cannula oxygen therapy in adults. J Intensive Care. 2015;3(1):15. doi: 10.1186/s40560-0150084-5. [PMID: 25866645]

38. Hutchings FA, Hilliard TN, Davis PJ. Heated humidified high-flow nasal cannula therapy in children. Arch Dis Child. 2015;100(6):571-5. doi: 10.1136/archdischild-2014-306590. [PMID: 25452315]

(c) The Internet Journal of Allied Health Sciences and Practice, 2017 